\title{
ESTADOS UNIDOS: ENSAIOS CONTRA O IMPÉRIO
}

\author{
Prof. Dr. Waldir José Rampinelli'
}

Davis, Mike. A apologia dos bárbaros: ensaios contra o império. São Paulo: Boitempo, 2008, 351 p.

O livro Apologia dos bárbaros, do historiador estadunidense Mike Davis, professor da Universidade da Califórnia, reúne escritos publicados entre 2001 e 2007 que analisam, sob diferentes perspectivas, a política interna e externa dos Estados Unidos, especialmente após os atentados de 11 de setembro de 2001.

Davis divide o trabalho em cinco partes, tendo por critério temas afins. No entanto, a linha de continuidade que perpassa a estrutura do livro é uma crítica perspicaz e fundamentada à Casa Branca, ao Congresso, ao Poder Judiciário, ao Pentágono, aos partidos políticos e às organizações sindicais que estão a serviço do grande capital e não dos interesses da população dos Estados Unidos.

Davis não acredita na afirmação de que "os estadunidenses colheram o que semearam” com os atentados às Torres Gêmeas, já que as principais vítimas daquela tragédia foram as secretárias, os contadores, os entregadores de lojas de conveniências, os lavadores de janelas, os corretores da bolsa e os bombeiros, pessoas que "não conceberam ou implementaram nossas políticas secretas, antidemocráticas e criminosas no mundo muçulmano"2. Responsáveis diretos pelos atentados, entre tantos, seriam, por exemplo, Madeleine Albright, secretária de Estado de Bill Clinton, que, ao responder a uma pergunta em rede nacional de TV sobre as 500 mil crianças mortas no Iraque como resultado das sanções impostas pelo governo dos Estados Unidos, asquerosamente afirmou: “Acredito que o custo compensou”. E o maior responsável de todos - George W. Bush - foi escolhido presidente por uma maioria na Suprema Corte e não pelos eleitores, tendo adotado poderes de guerra contra todos, em toda parte e para sempre, sem precedentes na história nacional dos Estados Unidos e, quiçá, mundial.

O autor de Apologia dos bárbaros não vê grandes diferenças entre o Partido Republicano e o Democrata, já que ambos estão ligados aos donos do poder econômico. Os socialistas estadunidenses, diz Davis, há anos vêm demonstrando que os democratas não passam de um partido capitalista com um verniz

I Professor do Departamento de História da UFSC. E-mail para contato: rampinelli@globo.com 
socialdemocrata. No entanto, as elites formadas por sindicalistas e por militantes dos direitos civis encontram sempre um pretexto para o velho vício, qual seja, a opção pelo mal menor. A história mostra, por exemplo, que a maioria democrata no Senado 1) vendeu a Bill of Rights (a Constituição dos Estados Unidos aprovada em 1787); 2) endossou cortes marciais e campos de concentração; 3) acatou a não assinatura do Protocolo de Kyoto e do Tratado sobre Mísseis Antibalísticos; 4) apoiou a militarização da fronteira mexicana e deu carta branca ao presidente George W. Bush para intervir na guerra suja da Colômbia; 5) aprovou, por meio do Comitê de Inteligência do Senado, a opção do uso de armas nucleares de "pequeno alcance" contra o dito Eixo do Mal”. Por fim, o democrata Joe Lieberman, ex-candidato à vice-presidência de $\mathrm{Al}$ Gore, defendeu com mais ênfase que os próprios republicanos o direito de invadir o Iraque, e Carl McCall promoveu sua campanha para governador de Nova York exibindo fotos em que aparecia disparando um fuzil M-16 em um campo de treinamento "antiterrorismo" israelense.

Uma política externa intervencionista compromete a própria democracia interna dos Estados Unidos. John Hobson, em seu Estúdio del imperialismo, criticava, no início do século XX, a voracidade da classe dominante inglesa em suas colônias espalhadas pelo mundo, ao tempo que mostrava que esta mesma elite, no afã de acumular sem limite, destruía a democracia interna londrina. O Ato Patriota, aprovado em 26 de outubro de 2001, quarenta e cinco dias após os ataques do 11 de Setembro, nada mais é que um conjunto de leis destinadas a aumentar a regulação, o controle e a fiscalização das atividades cotidianas dos cidadãos estadunidenses, exacerbando o poder de policiamento do governo. James Petras o denominou de fascismo amistoso. Noam Chomsky vai mais longe, chegando a dizer que "não devemos nos esquecer que os próprios EUA são um Estado líder do terrorismo”.

\section{Raça, classe e história}

Mike Davis, ao analisar a destruição de New Orleans pelo Katrina, mostra que todos os aspectos da catástrofe foram moldados por desigualdades de classe e raça. Pesquisadores de várias universidades do sul dos Estados Unidos vinham chamando a atenção das autoridades para a possibilidade do rompimento dos diques por falta de manutenção. No entanto, nada se fez para sanar o problema, já que a cidade era povoada por $75 \%$ de afro-americanos e por ter um alto índice de pobres, de criminosos e de desempregados. Foi a negligência federal, e não a fúria da natureza, a maior responsável pelo assassinato de New Orleans.

Utilizando-se do desastre natural, políticos inescrupulosos, especuladores imobiliários gananciosos e brancos racistas apostaram em uma higienização da 
metrópole do jazz. Um deles, Finis Shellnut, afirmou que "o furacão obrigou os pobres e os criminosos a saírem da cidade, e nós esperamos que eles não voltem. A festa dessa gente está quase no fim e agora eles terão de encontrar outro lugar para morar”3 . Outro, Joseph Canizaro, com laços pessoais que o ligam ao círculo interno da Casa Branca, disse que "essas pessoas pobres não têm condições de voltar para nossa cidade, assim como não tiveram condições de deixá-la. Então, não traremos todas de volta"4.

O governo Bush também aproveitou o pretexto do Katrina para atacar os sindicatos independentes, principalmente aqueles que defendiam os direitos dos trabalhadores e pressionavam pela contratação de moradores para recuperar New Orleans. Com isso, favoreceu as grandes corporações, como o Wal-Mart, que, combinando a tecnologia just in time com as características mais selvagens do capitalismo, tornou-se a empresa-símbolo da exploração. "Conhecida por pagar salários miseráveis e fraudar as horas extras de seu 1 milhão de empregados nos Estados Unidos”, comenta Davis, “o Wal-Mart age de forma ainda mais sinistra no estrangeiro, pressionando incessantemente seus milhares de fornecedores em Bangladesh, na China e na América Central para que reduzam os custos do trabalho e suprimam direitos trabalhistas. O Wal-Mart é, sem dúvida, o maior empregador indireto de mão-de-obra semiescrava ou infantil do planeta. A "walmartização" tornou-se, portanto, sinônimo de "corrida ao fundo do poço", completa abolição dos direitos do trabalhador e da cidadania"

O historiador Mike Davis critica os livros didáticos das escolas estadunidenses por sua ocultação da história. A Operação Bagration, de junho de 1944, por exemplo, que leva este nome em homenagem a um herói russo de 1812, foi um ataque soviético decisivo contra a retaguarda da poderosa Wehrmacht de Hitler. Para Davis, foi a batalha da libertação da Europa do nazi-fascismo. No entanto, não se encontra uma palavra sobre esta operação nos livros básicos de história nos Estados Unidos. E isso tudo, apesar de esta ofensiva de verão soviética - chamada pelo historiador Jon Erickson de o grande terremoto militar ter sido muito mais grandiosa que o desembarque na costa francesa, tanto em escala de forças envolvidas quanto em custo direto infligido aos alemães. Não tivesse havido a Bagration dificilmente aconteceria a Normandia.

O historiador Marc Ferro chama a esta omissão de tabu, lembrando que o mesmo não existia para os contemporâneos de então. “Todavia” - diz Ferro - "à medida que os anos passaram, que a guerra fria se instalou, que a historiografia ocidental se impôs, a parte e o papel que a potência soviética representou acaba-

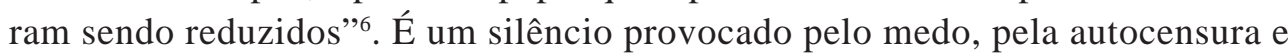
pelo pudor. Na luta contra o nazismo, cerca de quarenta Ivans morreram para cada soldado Ryan. "De fato”, diz Davis que “a maioria dos norte-americanos é 
espantosamente ignorante a respeito dos ônus dos combates e das baixas da Segunda Guerra Mundial. E mesmo a minoria que compreende algo da grandiosidade do sacrifício soviético tende a julgá-lo nos termos dos estereótipos crus do Exército Vermelho: uma horda bárbara conduzida por um sentimento cruel de vingança, um frenesi por estupros e um nacionalismo russo primitivo"7. O mesmo ocorreu na Rússia com os historiadores, que tendo acesso aos arquivos que comprovavam a importância de Leon Trostsky na criação do Exército Vermelho, preferiram a autocensura diante do terror de Estado ${ }^{8}$.

No que toca à América Latina, os livros didáticos omitem 1) que os negros haitianos, liderados por Toussaint L’Ouverture, no final do século XVIII, tiveram uma participação decisiva na manutenção da Luisiânia como território estadunidense, ao infligir uma derrota aos exércitos de Napoleão Bonaparte no Haiti, quando as forças francesas se preparavam para recolonizar aquela província; 2) apresentavam o Canal do Panamá como propriedade sua, não mencionando que a independência daquele país (1903) fora provocada por Washington, já que a Colômbia se negara a aceitar uma passagem inter-oceânica estrangeira em uma de suas províncias; 3) falam que a Amazônia deve estar sob a proteção da humanidade (leiam-se Estados Unidos) alegando sua importância ambiental, ecológica e de biodiversidade, sem comentar a exploração e a destruição já feita por alguns de seus empresários (Ford na borracha, com a Fordlândia; Ludovic na celulose, com o Projeto Jarí), sem mencionar o interesse das multinacionais ligadas aos medicamentos; 4) estampam o monumento aos Marines agarrados ao mastro de sua bandeira num visível esforço para fincá-la em solo estrangeiro com o intuito de levar a civilização aos bárbaros, lendo-se no pedestal do monumento as datas das intervenções armadas, sem dizer que as mesmas deixaram milhares de mortos e se prestavam à estratégia imperialista de buscar matériasprimas baratas e mercados cativos para seus produtos ${ }^{9}$.

O Pentágono, diz Davis, deveria estudar a história das colônias conquistadas e perdidas, dos impérios erguidos e derrubados, evitando, assim, a atual carnificina iraquiana. Bastava ler as cartas de Gertrude Bell e os diários de Winston Churchill, os homens que transformaram três prósperas e etnicamente distintas províncias do Império Otomano em um infeliz território britânico. Churchill, então secretário de Estado de Guerra e da Aeronáutica (1920), utilizou a estratégia dos bombardeios com armas químicas, como as bombas de gás mostarda, para economizar dinheiro e soldados na dominação do Iraque. Graças ao gás venenoso e aos tanques, os britânicos recuperaram o controle da região, em setembro de 1920, sem deixar de lado as expedições punitivas pelos territórios rebeldes, queimando vilarejos, executando suspeitos, confiscando mantimentos e aplicando multas. Mais tarde, a força aérea britânica bombardeava regiões do 
Iraque, como o baixo Eufrates, já não para reprimir tumultos e sim pressionar os vilarejos a pagar seus impostos. Em fins de 1921, Churchill observou com satisfação que seus aeroplanos haviam passado a ser temidos e continuou a defender o uso do gás venenoso no Iraque e em toda a região. Questionado por um coronel, subordinado seu, sobre os horrores causados pelos efeitos dos bombardeios, Churchill o repreendeu severamente dizendo que "não entendo essa aversão ao uso de gás. Sou totalmente a favor do uso de gás venenoso contra tribos incivilizadas" ${ }^{10}$. Certamente, fora este o mestre maior de Saddam Hussein. Apesar de tais métodos genocidas, a Grã-Bretanha saiu derrotada da região.

Apologia dos bárbaros mostra como a revolução revoluciona a contrarevolução. Por isso, o livro é importante para entender a política interna e externa dos Estados Unidos. Algumas ausências sentidas no trabalho foram as de Noam Chomsky, James Petras, Michael Klare e Immanuel Wallerstein, que trabalham igualmente as relações dos Estados Unidos no mundo. Um livro que ajuda a entender os meandros do império.

\section{NOTAS}

' DAVIS, Mike. A apologia dos bárbaros: ensaios contra o império. São Paulo: Boitempo, 2008, p. 24.

${ }^{2}$ Idem, p. 237.

${ }^{3}$ Ibidem, p. 236.

${ }^{4}$ Ibidem, p. 158.

${ }^{5}$ FERRO, Marc. Os tabus da história. Rio de Janeiro: Ediouro, 2003, p. 56.

${ }^{6}$ DAVIS, Mike. Op. cit, p. 282

${ }^{7}$ Idem, p. 20.

${ }^{8}$ RAMPINELLI, Waldir José. A história: uma arma de dominação. In: RAMPINELLI, Waldir José (Org.) História e poder: a reprodução das elites em Santa Catarina. Florianópolis: Editora Insular, 2003, p.3031 .

${ }^{9}$ DAVIS, Mike. Op. cit, p. II 4 